SOCIAL RESEARCH REPORTS

ISSN: 2066-6861 (print), ISSN: 2067-5941 (electronic)

\title{
INDIVIDUAL PARENTAL COACHING - A SUPPORT FOR PARENTS
}

\author{
Iris BARKAN
}

Social Research Reports, 2020, Vol. 12, Issue 1, pp. 39-53

The online version of this article can be found at:

www. researchreports.ro

\section{https://doi.org/10.33788/srr12.1.3 \\ Published by: \\ Expert Projects Publishing House

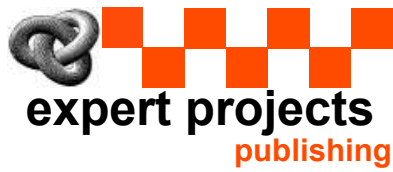

Covered by Index Copernicus International www.indexcopernicus.com

Directory of Open Access Journals www.doaj.org

On behalf of:

Center for Program and Social Development

Aditional services and information about Social Research Reports can be found at: www.researchreports.ro 


\title{
INDIVIDUAL PARENTAL COACHING - A SUPPORT FOR PARENTS
}

\author{
Iris BARKAN ${ }^{1}$
}

\begin{abstract}
Parents are usually entering the significant role of parenthood without any designated manual or training, apart from the parental modeling they have experienced in their own childhood home. Yet, the responsibility for raising happy and well-adjusted children lays on the parents' shoulders. The parental task becomes even more demanding during the tension saturated years of adolescence, when parents tend to feel lost, bewildered, and lose the easy-going communication they had with their children, especially in the challenging post-modern era. In order to establish 'good enough' parenting, which is based on a coherent and consistent agenda, parents should be given the opportunity to set out on a journey of familiarity with their own 'self,' their values as individuals, their beliefs, strengths and weaknesses, which is offered by using the Individual Parental Coaching (IPC) model. The uniqueness of the model is by placing the parents at the heart of the coaching process, relating to them as whole and complete persons, rather than as a parent designed to bare, raise, love and serve children. The model was examined with qualitative research in 2016 in Israel, and has developed to other fields since then. The results of the initial research and utterances from other parents that participated in the model in various contexts indicate that they clearly witness a significant improvement of their parental abilities, which lead to a better connection and communication with their adolescent's children.
\end{abstract}

Keywords: parenthood, Israeli parenthood, adolescence, coaching, parental coaching.

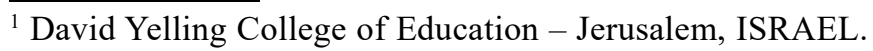




\section{Literature review}

\section{Parenthood}

Parenthood, is one of the most influential and significant roles in one's life (Austin, 2016; Cohler \& Musick, 2018), which requires no degree, manual or guidance. It has been vastly investigated and researched in the attempt to explain the complexity of the parenting role while trying to define the 'best' parenting model.

Up until the $19^{\text {th }}$ century, parents were the absolute authority, hence, hierarchy between parent child, was very rigid and explicit (Jenkins, 1998). Approximately towards the end of the $19^{\text {th }}$ into the $20^{\text {th }}$ century, due to global processes amongst them the development and understanding of child psychology, the concept of childhood as a crucial phase of life, was widely accepted. During the $20^{\text {th }}$ century, which was considered to be the "century of the child" a coined phrased Ellen Keys (apud. Michaelson, 2000), major changes of children and childhood perceptions occurred. Alongside these processes, the concept of the "parental role" evolved, and massively changed. Diana Baumrind (1966) one of the earliest, most appreciated researches in the field, based her typology of parenting styles on two aspects: 'Parental responsiveness' and 'Parental demandingness'. Based on these dimensions, she identified three different parenting styles: permissive, authoritarian and authoritative. Her typology, which is largely accepted and studied, has developed in recent years, and another parenting style was added - the Rejecting/Neglecting Parenting Style (Turel, 2003; Mensah \& Kuranchie, 2013). At the middle of the $20^{\text {th }}$ century, a more liberal, democratic and individualistic approach towards parenting arose, based on the principles of Adlerian and humanistic psychologies (Meredith, 1986; Miklikowska \& Hurme, 2011). Children were considered to be vulnerable, yet equal and authentic individuals, that should not be ruled by autocratic power of parents (Oryan \& Gastil, 2013). The research of parenthood, parenting and the quest for best parental practices, has evolved over the years and still does, along the years we can find quite a few models. An approach delineated by Holden (1983), stressed the importance of proactive parenting practices, believing that proactive control might have productive effects on social development. Dix (1991) viewed parenting first and foremost as an emotional experience, proposing an affective model of parenting that features three aspects which emphasize the child, the parents and the contextual factors that activate parent's emotions. Hoghughi \& Long (2004) defined parenting as purposive activities aimed at ensuring the survival and the development of children, with parental activities falling into three categories: care, control and development. Parenting, according to Pecnik, Daly, \& Laliere (2007), has kept in step with society, thus moving towards a more holistic concept of parenting emphasizing the interactions between parenting resources and capacities, the child's developmental needs, the family plus environmental factors. Joussemet, Landry \& Koestner (2008) proposed the application of the principles of self-determination theory to parenting. Self-determination is defined as the fundamental need of all human beings to feel competent and autonomous in order to develop optimally. According to Padilla-Walker (2011), proactive parenting involves anticipatory rather than reactive techniques. Last but not least, 
it is important to keep in mind those different cultures, which follow different core values, construct different types of parental emphasis and behaviors', as pointed out by Bornstein (2012).

\section{Israeli families and parenting}

Despite the understanding that Israel is experiencing similar global (western world) processes of individualization attributed to post-modernism and other social changes, many researches exploring the Israeli family and parenthood, find that these two components are still considered the most central and important in one's life (Fogiel-Bijaoui \& Rutlinger-Reiner, 2013; Scharf, 2014; Lavee \& Katz, 2003). All agree that familyism, meaning the centrality of the hetro-normative family, remains the identifying mark of the Israeli society. Marriage is still considered the most acceptable and legitimate framework for having children, it is the children and not the individual, who constitute the foundation of the family. Hence, the main role of women in Israel remains that of a wife and a mother. Israeli families tend to be stronger and more stable with a lesser divorce rate, than families in other industrialized nations, they usually have more children and gender roles are more traditional, maybe due to the fact that Jewish tradition and religion treat motherhood as the top priority for any woman. Within the Israeli society, it is perceived as being of national importance, thus making the mother and wife roles, prominent and self-evident for Israeli Jewish women (Sinai-Glazer \& Peled, 2017). Nonetheless, children are considered the most important part of a person's life, almost to the point where life is thought of as not worth living without them, as described by Lavee \& Katz: Israel is a 'child-oriented' society. Married couples are expected to have children, and a childless couple is not considered a family. Nearly $60 \%$ of Israelis believe that childless people have an 'empty life, 'and more than $80 \%$ believe that "the greatest joy in life is to follow children's growing up" (Lavee \& Katz, 2003: 203).

Children are seen as the center not only of the family, they are considered central to the entire Israeli society, where we find that children's needs are prioritized for a longer period than in other societies (Lavee \& Katz, 2003).

Israeli fatherhood, as opposed to Israeli motherhood and family, has not been as thoroughly researched. Yet, in his book 'fathers across cultures' Roopnarine (2015) devotes a chapter especially to Israeli fathers and fatherhood. Strier (2013, apud. Roopnarine, 2015) finds that Israeli fathers are in a slow constant change, which varies in different parts of Israeli society. Shapira (2013, apud. Roopnarine, 2015) claims that secular Jewish fathers show greater involvement in their children's affairs and there is more equal labor division in household matters than before. Israeli fathers are in constant conflict, as they challenge old traditions regarding fatherly roles, in the face of the globalization, modernization, westernization, and industrial environment in the State of Israel.

\section{Post-modernistic Parenthood}

The new era of humanistic, social and liberal approaches that emerged during the middle of the $20^{\text {th }}$ century, had a strong effect on the perception of parenthood. 
This was followed by the "post-modern" times, a progression that resulted in massive changes in family structures and parent-children relationships. While modern times were characterized by the belief in an objective reality and the existence of clear and binding values derived from it, the post-modern era brought a sense of transience, arbitrariness and loss of absolute values. The exclusive modern ideologies were largely replaced with the notion that everything is questionable, debatable, relative and pluralistic (Aviram, 1994). This major change produced great social openness and equality, yet it also caused a lack of clear role definition's, confusion in boundaries and ambiguity in many areas of life, including the concept of family. The 'ideal' modern family structure was challenged by divers' types of families that had previously been considered unacceptable (Omer, 2000). Women joined the workforce and pursued careers, fathers took a more active part in household chores, and new values became central in parents' lives. Self-fulfillment, individual rights and a great emphasis on the individual's special abilities and needs, led to the acknowledgment that children's thoughts, wishes and opinions, count.

Looking at the new millennium, we see further strain put on parents since the range of parental responsibilities has increased. It includes the need to attend to emotional development, physical wellbeing and an overall involvement in children's worlds of contents. It also requires parental supervision and mediation of reality due to advanced technology and greater exposure to information (Stearns, 2004). He claims that Parents deal with new levels of parenting anxiety, and it seems parental satisfaction has been declining during the $20^{\text {th }}$ century. Bernstein and Triger (2010) refers to modern parenthood as the "intensive parents", as today's parents are much more involved in their children's lives than were parents of previous generations. Locke, Campbell, \& Kavanagh (2012) claims that "Today, the child is a king" (2012: 1221) and calls this new social phenomenon 'overparenting', which is characterized by the intrusive presence in the child's life, the elevated overprotection and anxiety regarding the child. Despite obvious advantages to such involved parenting, Locke, Campbell, \& Kavanagh (2012) points out the possible repercussions such 'over-parenting' can have: children demonstrating low resilience, deficiency in life skills, lack of coping mechanism and high anxiety, just to name a few.

Contemporary parents are in a state of confusion, struggling to choose a coherent parental-educational agenda, in times where all is acceptable and negotiable, described by Dor (2004) as 'the parental fog'. Parents maneuver between the desire to be considered 'good' parents, and the strive to succeed as individuals in a materialistic, consuming, technological and demanding world.

\section{Adolescence}

By most theoreticians and psychologists, adolescence is considered to be a significant period in the human life cycle. Many have investigated the roles, behaviors, connections and ramifications of these meaningful years, back to the days of Aristotle and Socrates which referred to teenagers as being hot-tempered and insubordinate (Arnett, 1999). Stanley Hall (1904) which is considered by many to be the first psychologist to take on a scientific approach to adolescence, 
looks at that period, as a "storm and stress" one, that reflects emotional instability and frequent fluctuations between emotional extremes. Piaget (1958) looked at adolescence through the lens of cognitive development, moving from concrete thinking to a higher, more sophisticated and abstract form of rational thinking. Anna Freud (1969) noted this period as one of internal conflict, psychological disequilibrium and erratic behavior, caused by tensions and struggles between the drives and the ego. She thought that one of the primary tasks of adolescents is the integration of adult sexuality into their developing personality. Blos (1979) considered adolescence to be the second separation-individuation phase in life, where adolescents' struggle to distance themselves psychologically from their parents, and disengage from infantile objects and enter into the world of adults. Erikson which was one of the most important and accepted researchers of the human life cycle, saw the identity formation as the central process in adolescence how to establish a coherent sense of personal identity (Erikson, 1994a). He coined the term "psychosocial moratorium" - an accepted social delay of commitments, allowing for free experimentation with various social roles without facing the attached responsibilities, where adolescents are granted the time, they need to integrate the elements of their identity. Arnett (1999) argued that contemporary research consistently supports a modified 'storm and stress' thesis, considering adolescence as a time when variety of problems are more likely to arise than at any other stage in life. He distinguished between three main aspects of the 'storm and stress' concept: conflict with parents, mood disruptions, and risk behavior. Bohleber (2012), a contemporary psychoanalytical adolescent theoretician, emphasized the adolescent cognitive abilities and the central role that newly acquired abstract thinking capacities, play in the adolescents' ability to liberate themselves from primary relationships.

\section{Parent-Adolescent Relationship}

As well known, adolescence is one of the most conflict-ridden periods in parent-child relations, during those years, everything is subjected to criticism and becomes a potential argument. As partially explained by Montemayor (1983), this deterioration has two components: an increase in parent-adolescent conflict and the parental loss of power and influence over their adolescent child. There are many ways to explain parent-adolescent conflict, between them we can count differences between adolescents and parents when interpreting social situations, legitimate parental authority and boundaries are being renegotiated, the dichotomy between adolescents' ambition to separate from parents and establish his/her own unique self, when simultaneously maintaining parental connection and validation (Smetana, 1988; Youniss \& Ketterlinus, 1987). For many parents, the daunting task of adolescent parenting, is rather challenging yet, in a longitudinal study, Friesen et al. (2013) showed the importance of close parent-adolescent's relations in this crucial period and the positive impact on the adolescent's parenting behavior more than 15 years later. 


\section{Coaching}

Although coaching is a rather new methodology in the field of 'helping others', it has been widely studied and investigated. There are quite a few theories trying to trace its roots, yet many agree that it can be found in the $20^{\text {th }}$ century psychologists such as Adler, Jung, Rogers \& Seligman, which are considered to be the founding fathers of humanistic, positive psychologies. These new ideologies (back at the $20^{\text {th }}$ century) considered each person to be unique, whole and capable of change and growth. The heart of positive psychology, like coaching, lies in the practitioner's choice to shift attention away from pathology and pain and direct it toward strength, vision and dreams. The ideology of coaching, emphasizes empowering the positive resources, abilities and strengths, and focuses on understanding what makes life worth living, while helping people become more self-organized and self-directed (Williams \& Davis, 2002; Kauffman, 2006). The main purpose of any coaching process, is assisting the individual in maximizing their strengths, abilities and potential. 'life coaching' refers to the journey of helping generally adequately functioning people to learn, improve and maintain their skills, leading them to happiness, fulfilment, productiveness and generally speaking - higher 'performance' levels in their everyday life (Nelson-Jones, 2006; Dexter, Dexter, G. \& Irving 2010).

\section{Coaching Psychology}

Coaching psychology brings the psychological theory and research methodologies into the process of practical coaching, including research, evidence-based benefits, and proven work methods and models. It is the focus on the systematic application of evidence based behavioral science, that distinguishes coaching psychology from regular coaching (Palmer \& Whybrow, 2014).

\section{Parental coaching}

Ellam and Palmer (2006) distinguish between 'parent training program' which takes on a directive or instructional approach, and "parent coaching" which is designed to empower parents with the confidence and ability to find the answers themselves, using different models. Bamford, Mackew, \& Golawski (2012), emphasize that parental coaching is different from other intervention strategies since the coach is not a 'parental expert' trying to 'correct' parental mistakes. The coach does not criticize parents for their behavior and do not offer them a script to follow. Instead, he/she engages in asking 'powerful questions', which enable parents to understand themselves first, and then their children better. Such a process ultimately results in a significant positive impact on the relationship and communication between parents and children. 


\section{The IPC model's rational}

Parenthood is mostly perceived as a natural privilege, an innate ability that is instinctive, and unburdened by the need for a special degree or training program. Most couples, planning to start a family, will give more thought and consideration to mundane decisions, than to reflect, consider and discuss the complexity of becoming a parent. Such a process may result in encountering unexpected difficulties when becoming one, and even more so during adolescent years, where a great deal of confusion, frustration and friction, becomes a part of the day-to-day parent-teenager relationships.

As described above, raising children in the $21^{\text {st }}$, century presents great challenges to parents, some of them are the result of children's centrality, and some derive from lack of coherent parental agenda. This cause many parents to base their parenthood on a confused and sometimes even chaotic set of values, beliefs and priorities, that eventually lead to misguided parental conduct, decisions and choices.

The IPC model provides parents with the opportunity to undergo a personal journey, during which they are able to crystallize a meaningful and viable set of personal values, beliefs and boundaries. By allowing a moment for themselves as whole individuals, parents explore, familiarize and are able to achieve an improved sense of self, which results in a coherent personal and parental agenda that eventually leads to a substantial improvement in communication and relationships with their children, both young and teenagers.

\section{IPC model description}

The IPC model presented here, is a result of a qualitative research conducted in Israel in 2016 in the process of a $\mathrm{PhD}$ thesis. The initial research included seven heterosexual married couples, secular Jewish families (fourteen individuals), all had children, young and adolescents between the ages 13-18 residing at home. The research process was conducted over the period of six months and consisted of ten consecutive meeting with each couple, in which both parents attended (in addition to a pre-coaching session that was held prior to commencing and a summarize session held a few months post completing). Each coaching session was dedicated to a relevant issue for the participants, both as individuals and as parents. During the coaching process, various coaching methodologies were used, such as therapeutic cards, writing exercises, observation assignment etc.

\section{Coaching Sessions layout}

Pre-coaching session: Mutual acquaintance of the parents and the coach. This meeting is dedicated to get familiar with the coaching process, the requirements for participating, the readiness and motivation of both parents to take on an active and conscious role in the coaching process. 
First Session: 'The cycle of my life' - a methodology which gives parents the opportunity to authentically take a look at the 'here \& now' of their lives, trying to evaluate its component, i.e. - occupational life, leisure activities, marital life, parenthood, health etc.

Si: "I am content with my life in general, but it doesn't mean I have no place for advancement...happy, yet still have more wishes, more hopes, more ambitions, there is always room for change...

Second Session: 'Me as an adolescent' - when trying to understand and relate to the adolescent's world and experience, it is an important to go back in memory, trying to remember one's own experience of puberty.

Mi: "I was a very independent child; I think that as a teenager I practically grew up by myself; alone. I was considered a "good" girl...

Third Session: 'Fantasy parenthood' - a personal journey that leads parents to a brave and realistic look of themselves as parents - how do I perceive my parenthood, what do I think of myself as a parent, am I living the parental dream I had prior to having children?

Jack: I am stable, big like a tree... I try to hold everyone, to be O.K. with the children all the time...but still, it seems I can't really do it... I can't satisfy them all the time...

Fourth Session: 'It's all about values' - this meeting is dedicated to one of the most significant milestones in any given coaching process = Value Mapping (Dolan, 2011). Each parent needs to choose the most important personal values (only ten), by which they lead their lives in all aspects, including practicing parenthood.

Mi: "wait... I need a second... you said core values, so I'm starting to be honest with myself"

Fifth Session: 'Translating values into reality' - after mapping and choosing core values one wishes to lead their lives by, both as individuals and as a parental unit, this meeting is examining the practical aspects of deriving boundaries from the chosen values.

Avz: I consider the way they treat me as a parent, to be a "red light" a border they can't cross, I will not accept disrespect, dismissing tone... I will end it on the spot...I will not allow such a behavior

Sixth Session: 'What holds me down' - this meeting revolves around the issue of personal barriers, it invites and encourages parents to baldly look at themselves and discover the inner barriers that disrupt and prevent them from achieving their goals, whether personal, professional, marital or parental. 
Ar: " being addicted to my comfort zone is my number one barrier...not willing to change anything...I am stuck with my habits even thought I know I need to change some things...

Seventh Session: 'We are all unique' - this session which is complimentary to the previous one, enable parents to find their personal resources - the special abilities and skills, strengths, powers and talents each one possesses, and speak it out loud.

Mo: The truth is I have never said these good things about myself ... It was exciting. It's like injecting goodness directly into my vein

Eighth Session: 'The magical toolkit' - during this meeting, parents are presented with different methods and tools for improved interpersonal interactions and communication, such as attentive listening, giving up judgmental, sharing etc., all are beneficent in all human interactions and is obviously very important when communicating with teenagers.

Ninth Session: 'The new and improved' - after undergoing a journey of selfexploration during which personal components such as - values, strengths and weaknesses are reviewed, parents are requested to envision a renewed personal self-model, and how this improved and more conscious self, can reflect on a future parenthood model they wish to practice.

\section{Si: the ability to authentically listen, really listen to the children}

Hez: Family commitment, initiative and involvement together with the endless love I have for the kids and my wife, do everything for the family.

Tenth Session: This session is dedicated to the completing and summarizing of the entire process; parents are requested to identify significant insights, understandings and changes they are experiencing. Closing and farewell.

Ar: The fact that it treated us as people not only as parents and gave us tools, obviously got through down to the entire home and atmosphere (...)

Summarize session: Approximately 6 months after completing the coaching process, a meeting is set in order to discuss any difficulties or dilemmas the parents encounter post the coaching process. Yet another, not less important aim to this meeting, is giving parents an opportunity to share positive changes and experiences they had.

The IPC model was developed while being loyal to the concept that parents are complete and whole individuals prior to them being parents. It also bears in mind that they are the experts of their own family and children. Each family is somewhat different, hence there are not any definite rules or pre-written scripts parents should go by. On the contrary, parents should create their unique set of values, boundaries and behaviors, that derives from their personal agenda and beliefs and is suitable to them as leaders of the family, and to rest of the household 
members. This model is unique in the sense that it refers to parents as 'holistic independent individuals' while keeping their parental role in mind. It is designed to give parents an opportunity to focus on themselves as individuals, quite a rare opportunity in today's modern life style.

\section{Major themes reviled during the research}

Upon completing the research including all its components, a thorough qualitative analysis of the coaching sessions transcripts was done, in the attempt to discern the most prominent issues arising from the participants narratives, these are some of the most eminent finding:

Values and reality. After going through the thorough process of value mapping and the way they are manifested in every day's life, a few insights were made clear - When trying to map personal values, people tend to choose idealistic and superior ones, as opposed to real, authentic and realistic ones. The majority of parents are not aware of the core value that motivates them as individuals or parents, most of their values are taken in during their own socialization process. Hence, a great deal of any personal decisions including parental decisions and choices, are based on these values without conscious awareness or choice, we as humans, are inclined to act automatically. There is a big gap between parents' selected values (personal or family values) and their actual daily behavior.

Putting parents at the center. The participating parents were surprised to realize that the coaching sessions were intended to primarily focus on them as individuals, and only later on their parental role, they took great pleasure when realizing they are the heart of the research. Yet, a parallel process occurred, it appeared that most parents found it hard to be at the center of attention for a long time. They felt uncomfortable with unveiling their world, examining their beliefs, values and thoughts. In general, it appears easier for them to hold on to the "child as the center' model, which is the one most of us were raised upon, than directly confront and deal with themselves and their personal motivations as individuals.

Parents teenagers' relationship. Most parents feel that children are the most important thing in their lives, hence parenthood is their most important role. They were honestly telling of moments in which they felt lost, confused, not knowing how to address changes in their children going through puberty, not understanding what modifications they need to do within themselves as parents; admitting that most of their actions, do not result from a decision-making process or conscious choices, but rather a reactive mode to situations met in reality. Most parents were amazed to recognize and realize the scope of "double standards" behaviors they display expecting teenagers to behave in a certain way when they, as family leaders behaved in a complete opposite manner. 
Differences between mothers and fathers. The major differences between mothers and fathers derive from different levels of willingness and motivation to take an active part in a personal journey of defining a coherent set of values, beliefs and priorities. Mothers are more courageous in looking boldly into their parenting patterns and recognize any difficulties that need to be addressed. They are the ones to initiate and take active measures in order to implement the necessary changes. Fathers are usually less eager and somewhat reluctant to take an active part in the processes of consultation, training or guidance regarding their parenting skills. Yet, as time went by, there was a growing readiness of fathers to open up to higher levels of emotional discourse inherent to such a process.

Change related issues. The need for change comes up when parents realize that their status as parents changes; their influence, control and position has changed as their children become teenagers. Parents tend to have extreme reactions - some turn rigid, inflexible and strict, while others become more flexible, adjust and expand boundaries accordingly. Some totally give up any attempt to communicate with their teenagers and give them total freedom. Most parents wish to be a meaningful part in their teenagers' lives, but don't know how to go about it. Many parents admit it is easier for them to deal with concrete, cognitive and instrumental needs than trying to contain and fulfill emotional needs in this stormy, confused and fragile period of life, and they honestly wish to change that.

\section{Practical implementation of the IPC model}

After the IPC model elaborated above, was examined and authorized, it is used in various ways in different areas of activities, some are detailed below:

On an individual level: it is used in a privet coaching clinic, where parents turn to, either as couples or individually, for 10 consecutive sessions, which consists a full coaching process. It is designated for parents with children of all ages, although many parents tend to seek professional help and guidance, when their children reach puberty, a period of many disagreements, tension and confusion (see page 6 regarding adolescents). The coaching process aims to help parents redefine their personal core values, which is shaped into a coherent agenda that is in congruence with their parental one. This process enables them to conduct a clearer, consistent and secure parenthood, while minimizing points of conflicts and disputes with their children, especially throughout the turbulent adolescent years.

On a group level: conducting parental guidance groups, that gathers parents which share similar difficulties with their children, and wish to receive some guidance from a professional facilitator. Yet moreover, these parents wish to find a sympathetic ear of other parents that are in the same conditions, from which they can get some good practical advice. In this context of parental group coaching, the IPC model is used according to the plan (specified above) hence, parents are able to look within themselves in order to find answers, while also being exposed to other parents' quest for answers. The mutual exposure to others thoughts and feelings, gives a sense of partnership and alleviation when dealing with feelings of frustration, guilt and disappointment. All of these many parents experience, but 
are reluctant to share with others, which sometimes cause a sense of loneliness when practicing the parental role.

In the educational field: based on the IPC model and the vast experience obtained by working with many parents, a unique academic course was developed. It was especially tailored for the 'Adult Education Program' a distinct academic learning program which is designed for adult students, (age 30+ working people that wish get a B.A degree in education) in David Yellin College of Education in Jerusalem. Since the majority of these students are parents, many have adolescent children, it seemed almost necessary to offer them a practical course that deals with one of the major roles they have as parents. In the last two years this course is taught with great success, and has a great demand, unfortunately leaving some very interested students out of the class as a result of over demand. Due to the large number of participants, necessary adjustments were made, so it would suit all. The students-parents have the opportunity to experience and benefit the personal quest the IPC model offers, listen to other students' reflection and input and receive knowledge (both theoretical and practical) that serves them to achieve better parenthood. This course gives parents the platform to raise dilemmas they meet on their everyday lives with their children, and receive optional ways of dealing with them. The search for parental answers, derive from them becoming 'conscious parents' who act on the basis of awareness and choice, and not on an 'automatic pilot'. The feedback from the participants in the course is nothing less but enthusiastic, they feel the course gives them a practical and relevant response for their parental need, that has no guidance or support elsewhere.

\section{Voices from the field}

"I feel I have more tools to deal with her, how to look at things, which I used to think were the end of the world, I have different proportions now (...)

"I can feel the general atmosphere is different, less stressed, less judging (...) understanding that not everything that we as parents decide is right for them, is actually right. It's a great sacrifice to make..."

"What enabled the change for the better, were the coaching session through which we were exposed to the fact that there are things we need to change in ourselves and not in the children. We understood that there are many ways to resolve situations, but it is up to us to choose the way by the values we believe in, and always ask - what is more important?? Sometimes it's smart to make concessions over trivial things in the purpose of building an attentive, solid and confident relationship".

"Our new perceptions of how to be patient and tolerant; think for a moment before "freaking out" 
"The understanding that we are responsible for situations, it is our responsibility to make time for talking, spend quality time together, be patient and take care of the connection"

"My ability to understand that everything depends on my behavior and my attitude, I learned how to be attentive"

"I feel I yell much less, there is more conversation around the house, more communication and touch ...once I did it with one son, I noticed the other one is looking for it as well"

"following the sessions with you, it completely changed, I used to come home from work and start my second job, I wouldn't rest for a minute... nowadays, I find myself sitting with them for two hours, talking, watching TV shows..."

\section{Conclusion}

The IPC model enables parents to achieve two simultaneous goals: first, a genuine opportunity to delve into themselves; to explore different components of their personality; to define their core values, beliefs and principles. Once recognizing, defining and accept all of these personality building blocks, they are able to clarify and refine their individual essence and the way it all corresponds with their real life. The second one is a by-product of the first, after achieving an aware sense of self and understand the core that motivates them, acquiring new pragmatic parenting skills and behaviors is much easier. As stated before, as the result of living in an era where children take such a central position in a persons' life, when adolescents' moratorium last many years through which parents are expected to patiently 'hold their breath' and wait for the tempest to calm down, contemporary parents are often pushed to the back of the stage, IPC model offers them the opportunity they deserve to be treated as equally important as their children.

\section{References}

Arnett, J.J. (1999). Adolescent storm and stress, reconsidered. American Psychologist, 54(5), 317-326.

Austin, M.W. (2016). Conceptions of parenthood: Ethics and the family. Routledge.'

Aviram, A. (1994). Childhood in a postmodernist society. Social security a journal of wellbeing \& security, 41, 97-117.

Bamford, A., Mackew, N. \& Golawski, A. (2012). Coaching for parents: empowering parents to create positive relationships with their children. Coaching in Education: getting better results for students, educators and parents, pp.3-24.

Baumrind, D. (1966). Effects of authoritative parental control on child behavior. Child Development, 37(4), 887-907.

Bernstein, G. \& Triger, Z. (2010). Over-parenting. UC Davis L. Rev., 44, 1221. 
Blos, PP. (1979). Adolescent passage, International Universities Press.

Bohleber, W. (2012). Adolescence in the Mirror of Changing Psychoanalytic Theory. Adolescent Psychiatry, 2(1), 3-9.

Bornstein, M.H. (2012). Cultural Approaches to Parenting. Parenting, 12(2-3), 212-221.

Cohler, B.J., \& Musick, J.S. (2018). Adolescent parenthood and the transition to adulthood. In Transitions through adolescence (pp. 201-231). Psychology Press.'

Dexter, J., Dexter, G. \& Irving, J. (2010). An introduction to coaching, Sage.

Dix, T. (1991). The affective organization of parenting: Adaptive and maladaptive processes. Psychological bulletin, 110(1), 3-25. DOI: 10.1037/0033-2909.110.1.3

Dolan, S.L. (2011). Coaching by Values (CBV): A guide to success in the life of business and the business of life, Tel Aviv: iUniverse.

Dor, A. (2004). Parenting styles: conceptual framework for contemporary parenthood, PHD dissertation. Haifa: Haifa University.

Ellam, V. \& Palmer, S. (2006). Does Parent Coaching Improve the Quality of Parenting and Children's Behavior. The Coaching Psychologist, 2(1), 2(1). Leicester: British Psychological Society.

Erikson, E.H. (1994a). Identity: Youth and crisis, WW Norton \& Company.

Fogiel-Bijaoui, S., \& Rutlinger-Reiner, R. (2013). Guest editors' introduction: Rethinking the family in Israel. Israel studies review, 28(2), vii-xii.'

Freud, A., 1969. Adolescence - in the writings of Anna Freud, New York.

Friesen, M.D. et al. (2013). Quality of parent-child relations in adolescence and later adult parenting outcomes. Social Development, 22(3), 539-554.

Hall, S. (1904). Adolescence: Its Psychology and its relation to physiology, anthropology, sociology, sex, crime, religion, and education, New York.

Hoghughi, M.S. \& Long, N. (2004). Handbook of parenting: theory and research for practice, Sage.

Holden, G.W. (1983). Avoiding conflict: Mothers as tacticians in the supermarket. Child Development, 54(1), 233-240.

Jenkins, H. (1998). The children's culture reader, NYU Press.

Joussemet, M., Landry, R. \& Koestner, R., 2008. A self-determination theory perspective on parenting. Canadian Psychology, 49(3), 194-200. DOI: 10.1037/a0012754

Kauffman, C. (2006). Positive psychology: The science at the heart of coaching. In: C. Kauffman, Evidence based coaching handbook: Putting best practices to work for your clients, pp.219-253.

Lavee, Y. \& Katz, R. (2003). The family in Israel: Between tradition and modernity. Marriage \& Family Review, 35(1-2), 193-217.

Locke, J.Y., Campbell, M.A. \& Kavanagh, D., 2012. Can a parent do too much for their child? An examination by parenting professionals of the concept of overparenting. Australian Journal of Guidance and Counselling, 22(2), 249-265.

Mensah, M.K. \& Kuranchie, A. (2013). Influence of parenting styles on the social development of children. Academic Journal of Interdisciplinary Studies, 2(3), 123-129. DOI: 10.5901/ajis.2013.v2n3p123

Meredith, C.W. (1986). Democracy in the family. Individual Psychology, 42(4), 602.

Michaelson, ,R(2000 . The century of the child - beginning and end. http://cms. education.gov.il/NR/rdonlyres/DBE24CCC-3BE6-445F-BD77-1C27BEC0A09B/ 181867/2013.pdf 
Miklikowska, M. \& Hurme, H. (2011). Democracy begins at home: Democratic parenting and adolescents' support for democratic values. European Journal of Developmental Psychology, 8(5), 541-557.

Montemayor, R. (1983). Parents and adolescents in conflict: All families some of the time and some families most of the time. The Journal of Early Adolescence, 3(1-2), 83-103.

Nelson-Jones, R. (2006). Human relationship skills: coaching and self-coaching, Routledge.

Omer, H. (2000). Parental presence. Reclaiming a leadership role in bringing up our children. Zeig, Tucker, Phoenix.

Oryan, S. \& Gastil, J. (2013). Democratic parenting: paradoxical messages in democratic parent education theories. International Review of Education, 59, 113-129.

Palmer, S. \& Whybrow, A. (2014). Handbook of coaching psychology: A guide for practitioners, Routledge.

Pecnik, N., Daly, M. \& Laliere, C. (2007). Towards a vision of parenting in the best interest of the child. Parenting in Contemporary Europe: A Positive Approach, Strasbourg: Council of Europe Publishing, pp.15-35.

Roopnarine, J.L. (2015). Fathers Across Cultures: The Importance, Roles, and Diverse Practices of Dads: The Importance, Roles, and Diverse Practices of Dads, ABCCLIO.

Scharf, M. (2014). Parenting in Israel: Together hand in hand, you are mine and I am yours. In Parenting across cultures. Springer, pp. 193-206.

Sinai-Glazer, H. \& Peled, E. (2017). The perceptions of motherhood among family social workers in social services departments in Israel. The British Journal of Social Work, 47(5), 1482-1499. DOI: 10.1093/bjsw/bcw111

Smetana, J.G. (1988). Concepts of self and social convention: Adolescents' and parents' reasoning about hypothetical and actual family conflicts. In: Minnesota symposia on child psychology. pp. 79-122.

Stearns, P.N. (2004). Anxious parents: A history of modern childrearing in America, NYU Press.

Turel, M. (2003). Parenting, authority \& adolescence. Promoting the status of women, Israel, Ministry of Education, Culture \& Sport.

Williams, PP., \& Davis, D.C. (2002). Therapist as life coach, New York: WW Norton \& Company.

Youniss, J. \& Ketterlinus, R.D. (1987). Communication and connectedness in mother-and father-adolescent relationships. Journal of Youth and Adolescence, 16(3), 265-280. 